\title{
Stress-induced microglial activation occurs through $\beta$-adrenergic receptor: noradrenaline as a key neurotransmitter in microglial activation
}

Shuei Sugama ${ }^{1 *}$ (D), Takato Takenouchi ${ }^{2}$, Makoto Hashimoto ${ }^{3}$, Hisayuki Ohata ${ }^{1}$, Yasuhiro Takenaka ${ }^{1}$ and Yoshihiko Kakinuma'

\begin{abstract}
Background: The involvement of microglia in neuroinflammatory responses has been extensively demonstrated. Recent animal studies have shown that exposure to either acute or chronic stress induces robust microglial activation in the brain. In the present study, we investigated the underlying mechanism of brain microglial activation by acute stress.
\end{abstract}

Methods: We first looked at the spatial distribution of the noradrenaline (NA)-synthesizing enzyme, DBH (dopamine $\beta$-hydroxylase), in comparison with NA receptors - $\beta 1, \beta 2$, and $\beta 3$ adrenergic receptors ( $\beta 1-A R, \beta 2-A R$, and $\beta 3-A R$ ) after which we examined the effects of the $\beta$-blocker propranolol and a-blockers prazosin and yohimbine on stressinduced microglial activation. Finally, we compared stress-induced microglial activation between wild-type (WT) mice and double-knockout (DKO) mice lacking $\beta 1-A R$ and $\beta 2-A R$.

Results: The results demonstrated that (1) microglial activation occurred in most studied brain regions, including the hippocampus (HC), thalamus (TM), and hypothalamus (HT); (2) within these three brain regions, the NAsynthesizing enzyme DBH was densely stained in the neuronal fibers; (3) $\beta 1-A R$ and $\beta 2-A R$, but not $\beta 3-A R$, are detected in the whole brain, and $\beta 1-A R$ and $\beta 2-A R$ are co-localized with microglial cells, as observed by laser scanning microscopy; (4) $\beta$-blocker treatment inhibited microglial activation in terms of morphology and count through the whole brain; $a$-blockers did not show such effect; (5) unlike WT mice, DKO mice exhibited substantial inhibition of stress-induced microglial activation in the brain.

Conclusions: We demonstrate that neurons/microglia may interact with NA via $\beta 1-A R$ and $\beta 2-A R$.

Keywords: Microglia, Restraint stress, Brain, CNS, Neuroimmunomodulation

\section{Background}

Stress, both physical and psychological, is a risk factor for neurodegenerative disorders such as Parkinson's disease (PD) and Alzheimer's disease (AD) [20, 39, 50], which have been associated with neuroinflammation and gliosis. Microglia are immunocompetent brain cells that contribute to neuroinflammation and gliosis. They usually display a ramified morphology, with long dendrites

\footnotetext{
*Correspondence: sugama@nms.ac.jp

'Department of Physiology, Nippon Medical School, 1-1-5 Sendagi Bunkyo-ku, Tokyo 113-8602, Japan

Full list of author information is available at the end of the article
}

and small cell somas, and are activated by various stimuli, including axotomy, inflammation, and neuronal damage [21,34]. The microglia can be morphologically classified into several types: ramified, hyper-ramified, reactive, and phagocytic. The phagocytic cell can further be differentiated into transitional (T-stage), motile (Mstage), and locomotor (L-stage) $[53,68]$. Once activated, microglia either phagocytize damaged neurons in a cellto-cell contact fashion $[19,45,54]$ or further harm injured neurons by releasing cytotoxic factors, such as nitric oxide, cytokines, chemokines, and reactive oxygen

(c) The Author(s). 2019 Open Access This article is distributed under the terms of the Creative Commons Attribution 4.0 International License (http://creativecommons.org/licenses/by/4.0/), which permits unrestricted use, distribution, and reproduction in any medium, provided you give appropriate credit to the original author(s) and the source, provide a link to the Creative Commons license, and indicate if changes were made. The Creative Commons Public Domain Dedication waiver (http://creativecommons.org/publicdomain/zero/1.0/) applies to the data made available in this article, unless otherwise stated. 
species $[10,18,36]$. Thus, controlling the microglial status is critical for maintaining normal brain activity.

One intriguing feature of microglia is their rapid response to stressful events such as acute [57, 76] or repeated $[42,46,59,66]$ stress, social defeat $[35,52,72]$, occlusal teeth disharmony [33], myocardial infarction [48], alcohol [69], sleep deprivation [4, 25], and hypertension [7]. Interestingly, microglial activation is also detected in psychiatric disorders such as depression $[65,75]$, bipolar disorder [23], and autism [63]. Using an in vivo rodent model, we demonstrated previously that, upon exposure to acute restraint/water immersion stress, microglia immediately become activated [57]. To our knowledge, this report might be the first one demonstrating stress-induced microglial activation $[49,68]$, although microglial activation has been reported in various models of acute, subacute, and chronic stress [11, 68, 69]. Regardless of the stress type, it is conceivable that microglia respond to "common" signals generated by stress responses. However, the molecular mechanisms underlying stressrelated microglial activation remain unknown.

In our previous study, we demonstrated that stressinduced microglial activation occurs within $30 \mathrm{~min}$ of exposure to restraint/water immersion stress [57]. This indicates the involvement of fast signals, such as those conveyed by neurotransmitters.

NA is the best documented neurotransmitter in stress experiments. For instance, NA has been reported to increase in the brain in response to various types of stresses including immobilization, foot shock, tail pinch $[17,44,62]$. In addition, administration of $\beta$ AR agonist, isoproterenol, significantly increased interleukin-1 $\beta$ (IL$1 \beta)$ in the brain [30, 74], and cultured microglia [64]. Besides, microglial activation induced by repeated social defeat is completely blocked by propranolol, an antagonist of $\beta 1$ and $\beta 2$ ARs ( $\beta 1-A R$ and $\beta 2-A R$ ) [72]. Furthermore, the induction of IL-1 $\beta$ in the hypothalamus (HT) by foot shock stress is blocked by propranolol $[8,9]$, which also inhibits proinflammatory cytokine production in microglial cells isolated from rats [71]. Collectively, these results suggest that microglia may receive noradrenergic signals in stressed brains. Therefore, we hypothesize that the sympathetic nervous system, most likely noradrenergic neurons, may control the microglial activation status. Here, we demonstrate a possible mechanism for stress-induced microglial activation.

\section{Methods}

\section{Animals and treatments}

All procedures were approved by the Institutional Animal Care and Use Committee of the Nippon Medical School (permission no. 27-052; Tokyo, Japan) and were performed in accordance with the National Institutes of Health Guide for the Care and Use of Laboratory
Animals, aiming to minimize the number of animals used and their suffering. Fischer rats (F344, males, 250$280 \mathrm{~g}$ ), known to be a stress-sensitive strain, were purchased from Japan Laboratory Animals, Inc. (Tokyo, Japan). For stress experiments, the animals were restrained with wire nets for 1-4h. Restraint stress (RS) was started at 10:00 a.m. and ended at 11:00 a.m., 12:00 a.m., and 2:00 p.m. (Fig. 1a). The rats were pretreated with the $\beta$-blocker propranolol $(10 \mathrm{mg} / \mathrm{kg}$ ) (P0884-1G; Sigma-Aldrich, St. Louis, MO, USA) and the $\alpha$-blockers prazosin (0.5 mg/kg) (P7791-50MG; Sigma-Aldrich) and yohimbine $\quad(3.0 \mathrm{mg} / \mathrm{kg}) \quad$ (Y3125-1G; Sigma-Aldrich), which were administered intraperitoneally, $1 \mathrm{~h}$ before the experiments. All animals were sacrificed immediately after the RS. Age-matched, unstressed animals, sacrificed immediately after being removed from the animal room, were used as controls. All animals were housed, with Fischer rats two to three and mice two to five in a cage, in a room with controlled temperature $\left(21 \pm 1^{\circ} \mathrm{C}\right)$, on a 12:12 light:dark cycle with lights on at 7:00 a.m, with food and water provided ad libitum access.

\section{Double-knockout mice}

Homozygous null mice (Adrb1 ${ }^{\text {tm1Bkk }}$ Adrb2 $2^{\text {tm1Bkk }} / \mathrm{J}$; stock no. 003810) for the Adrb1 and Adrb2 mice were obtained from the Jackson Laboratory and genotypes were confirmed as described by the Jackson Laboratory. Briefly, two separate PCR reactions were set up for each genomic DNA sample, one for adrb1 and one for Adrb2. Both PCR reactions were performed at $95^{\circ} \mathrm{C}$ for $2 \mathrm{~min}$, $\left(95^{\circ} \mathrm{C}\right.$ for $30 \mathrm{~s}, 56^{\circ} \mathrm{C}$ for $30 \mathrm{~s}, 72^{\circ} \mathrm{C}$ for $\left.45 \mathrm{~s}\right), 35$ cycles, $72^{\circ} \mathrm{C}$ for $5 \mathrm{~min}$, hold at $4{ }^{\circ} \mathrm{C}$. Primers for Adrb1 include WT forward (5' ${ }^{\prime}$ CTG ATC TGG TCA TGG GAT TG$\left.3^{\prime}\right)$, WT reverse $\left(5^{\prime}\right.$-GCG ATG ACA CAC AGG GTC T-3'), Mutant forward (5'-CGC TGT CCA CAG TGG TTG T-3') Mutant reverse (5'-TGG CTA CCC GTG ATA TTG CT-3'), Primers for Adrb2 include common reverse (5'-CCG GGA ATA GAC AAA GAC CA-3'), WT forward (5' ${ }^{\prime}$ ACC AAG AAT AAG GCC CGA GT$\left.3^{\prime}\right)$, and Mutant forward 5' -CAC GAG ACT AGT GAG ACG TG-3').

\section{Immunohistochemistry (IHC)}

Immunohistochemical analyses were performed as previously described, with minor modifications [51]. The following primary antibodies and dilutions were used: OX-42 (1:1,000; Serotec, Oxford, UK), Iba1 (1:1,000; Wako Pure Chemical Industries, Osaka, Japan), CD11b (1:1,000; Serotec), DBH (1:1,000; Millipore, Bedford, MA, USA), Ki 67 (1:1,000: Abcam), Cleaved caspase 3 (1:1,000: Cell Signaling, MA, USA), $\beta 1$-adrenergic receptor (AR) (1:1,000; Santa Cruz Biotechnology, Santa Cruz, CA, USA), $\beta 2-A R$ (1:1,000; Santa Cruz Biotechnology), and $\beta 3-A R$ (1:1,000; Santa Cruz Biotechnology). After 


\section{A Experimental Protocol}

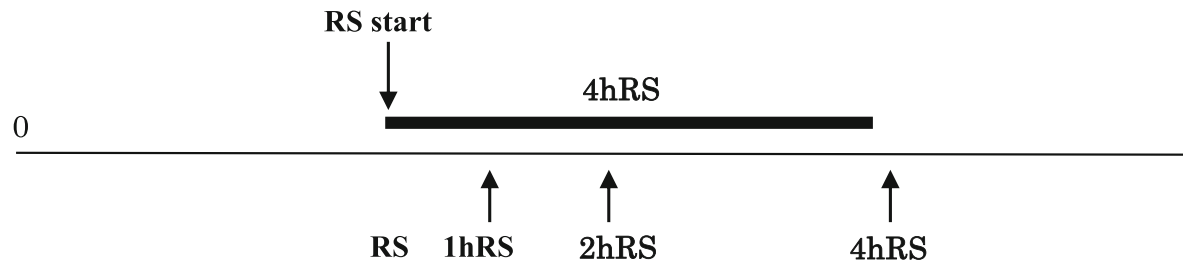

B

Corticosterone (CORT) measurement

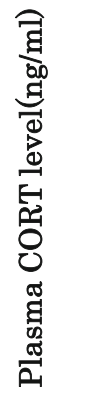

ర్య

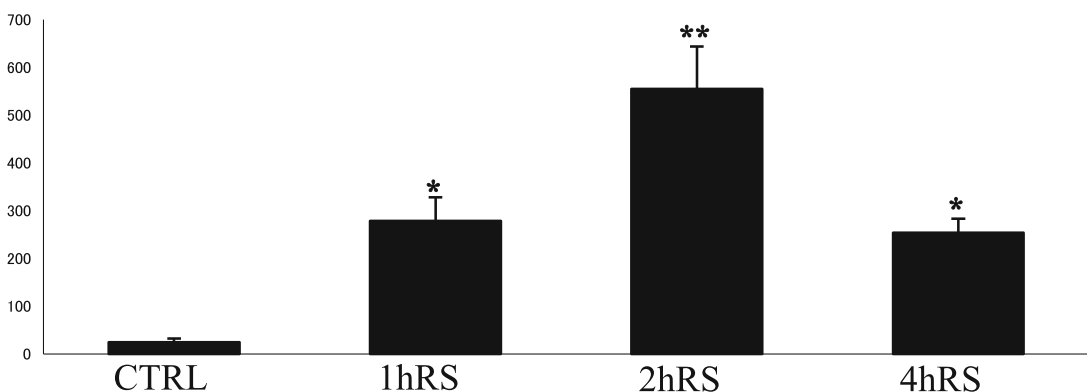

Fig. 1 a A schematic depiction of the acute RS protocol. Fischer rats were subjected to acute RS for $1-4 \mathrm{~h}$. b Plasma corticosterone levels (ng/mL) under control conditions and acute RS. The asterisks indicate the statistical difference between acute RS rats and control rats $\left({ }^{*} p<0.05,{ }^{* *} p<0.01, n=4\right)$

PBSTx rinses, the sections were incubated with biotinylated secondary antibody (Vector Laboratories, Burlingame, CA, USA) for $60 \mathrm{~min}$ at $1: 200$ in $0.1 \mathrm{M} \mathrm{PBST}$ containing 1\% BSA. Following rinsing, the sections were exposed to avidin-biotin horseradish peroxidase complex in $0.1 \mathrm{M} \mathrm{PBST}$. Antigens were visualized through reaction with $0.05 \% 3,3^{\prime}$-diaminobenzidine tetrahydrochloride as a chromogen in PBS and $0.003 \%$ hydrogen peroxide for 5 min. The sections were mounted on gelatin-coated slides, dehydrated, and coverslipped with Multi-Mount (Matsunami Glass Ind., Ltd., Osaka, Japan).

For immunofluorescence, the following primary antibodies and dilutions were used: OX-42 (1:200), DBH (1: 200), $\beta 1$-AR (1:200), $\beta 2$-AR (1:200), and $\beta 3$-AR (1:200).

\section{In situ hybridization (ISH)}

ISH was performed as previously described, with minor modifications $[56,59]$. Tissues were prehybridized in a hybridization solution (50\% formamide, $5 \%$ dextran sulfate, $1 \times$ Denhardt's solution, $0.25 \%$ SDS, $200 \mu \mathrm{g} / \mathrm{mL} E$. coli transfer RNA, $600 \mathrm{mM} \mathrm{NaCl}$, and $1 \mathrm{mM}$ ethylenediaminetetraacetic acid [EDTA]). Digoxigenin- (DIG-) labeled sense and antisense RNA probes were synthesized from the template cDNA (tyrosine hydroxylase $(\mathrm{TH})$, $\beta 1-A R, \beta 2-A R$, and $\beta 3-A R)$, which was subcloned into pGEM-T Easy Vector (Promega, Madison, WI, USA) using a DIG RNA labeling kit (Roche Diagnostics, Mannheim, Germany). SP6 RNA polymerase was used for antisense probe labeling with SphI (restriction enzyme) cut plasmid, whereas T7 RNA polymerase was used for sense probe labeling with SpeI (restriction enzyme) cut plasmid.

Reverse transcriptase-polymerase chain reaction (RT-PCR) Total RNA was isolated from the brain tissues using the RNA extraction buffer ISOGEN (Nippon Gene, Tokyo, Japan). cDNA was synthesized from $2 \mu \mathrm{g}$ of total RNA using SuperScript III First-Strand Synthesis System (Invitrogen, Carlsbad, CA, USA) according to the manufacturer's instructions. PCR amplification was performed with Taq PCR polymerase (ABgene, Tokyo, Japan), and the amplified products were dissolved by agarose gel electrophoresis. The sequence of primers used for PCR is as follows: rat GAPDH: 5' -CCT TCA TTG ACC TCA ACT ACA TGG T-3' and 5' ${ }^{\prime}$ TCA TTG TCA TAC CAG GAA ATG AGC-3'; rat $\beta 1-A R: 5^{\prime}-\mathrm{CAT}$ CGT 
GGT GGG TAA CGT GCG G-3' and 5'-AAA TCG CAG CAC TTG GGG TC-3'; rat $\beta 2-\mathrm{AR}: 5^{\prime}$-ACC TCC TTT TTG CCT ATC CA-3' and 5'-TAG GTT TTC GAA GAA GAC CT-3'; rat $33-A R: 5^{\prime}-\mathrm{TCC}$ CCT CCT TGT GAT GCT-3' and 5'-AAC GGA CGC GCA CCT TCA-3'. PCR assays comprised an initial $10 \mathrm{~min}, 94{ }^{\circ} \mathrm{C}$ step to activate Taq polymerase, followed by 36 cycles of denaturation at $94{ }^{\circ} \mathrm{C}$ for $10 \mathrm{~s}$, annealing at $55^{\circ} \mathrm{C}$ for 10 $\mathrm{s}$, and extension at $72{ }^{\circ} \mathrm{C}$ for $25 \mathrm{~s}$.

\section{Quantification of immunoreactivity and ISH}

In order to quantify immunohistochemical signals and ISH, the mean optical densities (ODs), defined as the average of the ODs within the target area, were measured from each section using the image analysis software WinROOF (Mitani Corporation, Tokyo, Japan) [51].

\section{Cell counting, cell size measurement, and Sholl analysis}

The Iba1-immunoreactive (Iba1-ir) microglial cells of the hippocampus (HC) (comprising the unilateral DG area), the thalamus (TM), and the HT were counted in a $200 \times 200 \mu \mathrm{m}$ square using WinROOF. For the cell size measurement, all pixels with gray level values below the threshold value were treated as belonging to cell image, and other pixels were treated as background. The appropriate threshold value was determined as the level at which the binary overlay completely covered the entire cell body and processes. Cell surface area was measured using binary images of cells, microglia and astrocyte, with image analysis software (WinROOF). To further evaluate the morphological changes, we performed Sholl analysis for microglial cells as well as astrocytes [13]. Briefly, circles of diameter ranging from 0 to $40 \mu \mathrm{m}$, with $10 \mu \mathrm{m}$ interval, were placed on the imaged cells, with each ring centered on the soma of each single cell. Intersections between the ring and the cell dendrites were counted using the image analysis software LuminaVision (Mitani Corporation, Tokyo, Japan), and the intersection count were averaged for all cells in images from each animal on different experimental conditions [67] (Fig. 6C).

\section{Enzyme-linked immunosorbent assay (ELISA) for corticosterone measurement}

Blood was collected into a tube containing EDTA. After $30 \mathrm{~min}$ of centrifugation, the plasma samples were stored at $-80^{\circ} \mathrm{C}$ until used for the measurements. Corticosterone levels were measured using an ELISA kit (Cayman Chemical Company, Ann Arbor, MI, USA).

\section{Statistical analysis}

Results are presented as the mean \pm standard error of the mean (SEM). All statistical analyses were performed with SPSS software (IBM, Chicago, IL, USA). Statistical significance was determined by Student's $t$ test and one-way and two-way analysis of variance (ANOVA). ANOVA was followed by Bonferroni's test for multiple comparisons. A level of $p<0.05$ was considered statistically significant. All results were obtained from four rats and experiments under each condition.

\section{Results \\ Monitoring stress levels with CORT in the plasma of rats exposed to acute stress}

First, the stress levels of Fischer rats exposed to acute RS were monitored via the quantification of plasma corticosterone, following the stress procedure (Fig. 1b).

Plasma corticosterone levels significantly increased from $24.0 \pm 7.9 \mathrm{ng} / \mathrm{mL}$ (under control conditions) to $278.7 \pm$ $49.3 \mathrm{ng} / \mathrm{mL}$ at $1 \mathrm{~h} \mathrm{RS}(n=4, p<0.05)$ and to $554.7 \pm 88.8$ $\mathrm{ng} / \mathrm{mL}$ at $2 \mathrm{~h}$ RS $(n=4, p<0.01)$, slightly decreasing to $253.9 \pm 28.7 \mathrm{ng} / \mathrm{mL}$ at $4 \mathrm{~h}$ RS $(n=4, p<0.05)$ (Fig. 1b). Consistent with previous reports $[28,29]$, corticosterone levels peaked in the middle of stress duration. The four groups differed significantly in terms of the stress effect $(n$ $=4, F(3,12)=22.479, p<0.001$; one-way ANOVA), suggesting that $1-4 \mathrm{~h}$ exposure to acute RS effectively induces stress responses in Fischer rats.

\section{Microglial activation following acute RS}

Next, we investigated microglial morphological changes. Under control conditions, resting microglia are distributed throughout the HT, HC, and TM. Following RS, microglia altered their morphology, becoming enlarged with shorter processes and enlarged soma in the HT, HC, and TM (Fig. 2A). The analysis based on cell size measurement showed a significant increase of Iba1-ir microglial cell size in the HT $(n=4, F(3,12)=17.355, p<0.001$; oneway ANOVA), $\mathrm{HC}(n=4, F(3,12)=3.962, p<0.05$; oneway ANOVA), and TM $(n=4, F(3,12)=3.561, p<0.05$; one-way ANOVA) (Fig. 2C). This morphological activation was not observed in astrocytes (Fig. 2B, D). This indicates the occurrence of morphological activation of microglial cells, but not astrocytes, following acute RS in Fischer rats. In addition, RS significantly increased the number of Iba1-ir microglia in the TM $(n=4, F(3,12)=4.079, p<0.05$; oneway ANOVA), but not in the HT $(n=4, F(3,12)=3.066, p$ $=0.069$; one-way ANOVA $)$ or $\mathrm{HC}(n=4, F(3,12)=3.066, p$ $=0.069$; one-way ANOVA) (Fig. $2 \mathrm{E}$ ). With regard to the microglial increases, we found no immunoreactivities to Ki67, a marker for proliferation through mitosis, in the HT that showed significant increase of microglia (Fig. 2F). These results suggest that microglia respond to acute RS by changing the cell morphology and increasing Iba1 expression, presumably not through cell proliferation.

\section{DBH-ir neuronal fibers in the $\mathrm{HT}, \mathrm{TM}$, and $\mathrm{HC}$}

Microglia possess ARs [41, 61], suggesting communication with noradrenergic neurons. Therefore, we investigated 

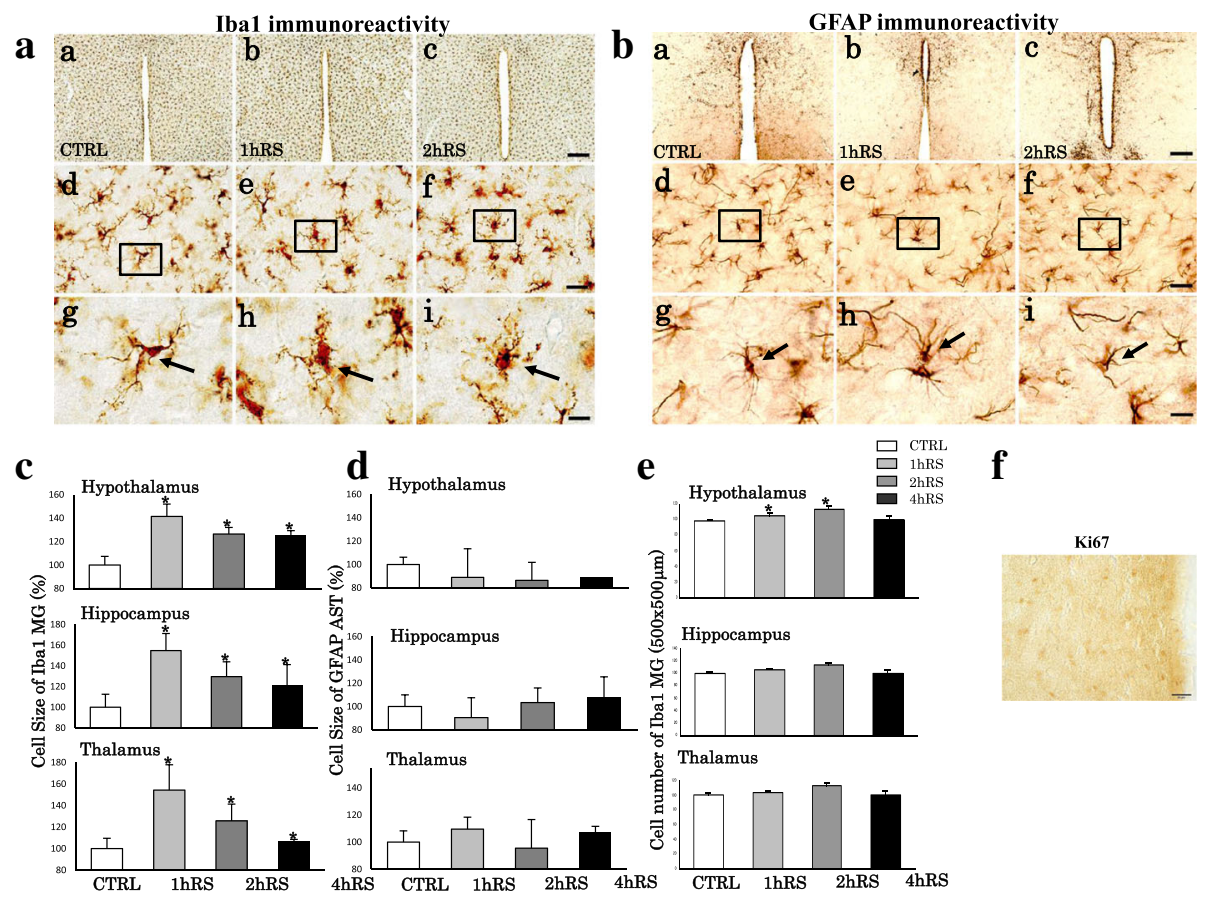

Fig. 2 A, B Morphological changes of Iba1-ir (A) and GFAP-ir (B) cells following RS in the HT. The upper panels show low-power photomicrographs of Iba1 and GFAP immunoreactivity in the HT of the control (CTRL) (a), 1 h RS (b), and $2 \mathrm{~h}$ RS (c). Panels (d), (e), and ( $f$ ) are enlargements of panels (a), (b), and (c), respectively. Panels (g), (h), and (i) are enlargements of boxed areas (d), (e), and (f), respectively. Arrows indicate resting (g) and activated (h, i) microglia. Scale bar: $200 \mu \mathrm{m}$ at low-power, $20 \mu \mathrm{m}$ at middle-power, and $10 \mu \mathrm{m}$ at high-power magnification. C, D Histograms showing the quantification of the cell size of Iba1-ir microglia and GFAP-ir astrocytes in the HT, HC, and TM at $\mathrm{CTRL}, 1 \mathrm{~h} \mathrm{RS}, 2 \mathrm{~h}$ RS, and $4 \mathrm{~h} \mathrm{RS}$, respectively. E Histograms showing the number of Iba1-ir microglia in the HT, HC, and TM at CTRL, $1 \mathrm{~h} \mathrm{RS}, 2 \mathrm{~h} \mathrm{RS}$, and $4 \mathrm{~h}$ RS, respectively. The asterisks indicate a statistical difference between post-RS and control for each group. ${ }^{*} p<0.05, n=4$. Data are presented as means \pm SEM. F No immunoreactivity to Ki67 was detected in the HT at $1 \mathrm{~h}$ RS. Scale bar: $10 \mu \mathrm{m}$

the immunoreactivity of $\mathrm{DBH}$, the specific enzyme that yields NA from dopamine, in the locus coeruleus (LC), HT, TM, and HC.

IHC revealed that DBH-ir fibers extended to the HT, TM, and HC (Fig. 3a). DBH-ir fibers were also detected in most brain regions, including the cerebral cortex $(\mathrm{CCx})$, periaqueductal gray (PAG), and substantia nigra (SN) (Fig. 3a).

Double IHC, using OX-42 and DBH, revealed that the fibers of DBH-ir neurons were extended, surrounding microglial cells in the HC, TM, and HT (data not shown). Furthermore, confocal immunofluorescence revealed that, in the $\mathrm{HC}$, OX-42-ir microglia were meticulously surrounded by DBH-ir fibers (Fig. 3b, upper panels). Z-stack analysis, which investigates 3D structures, clearly demonstrated DBH-ir fibers framing the OX-42-ir microglial cells (Fig. 3b, lower panels). Furthermore, Z-stack analysis demonstrated the co-localization of DBH-ir fibers and OX-42-ir microglial cells in other regions such as $\mathrm{HC}$ and $\mathrm{CCx}$ (Fig. 3c). This finding was also confirmed with a different combination with Iba1DBH staining which demonstrated the DBH-ir fibers surrounding Iba1-ir microglial cells in the HT (Fig. 3d).

\section{Noradrenergic neuronal activation in the LC, but not in the SN}

It is well known that the cell bodies, projecting DBH-ir axons to a variety of brain regions as shown in Fig. 2A, are located in the LC. To demonstrate the noradrenergic neuronal activation, we measured TH mRNA in the LC and SN. TH mRNA significantly increased in the LC following acute stress $(n=4, F(3,12)=21.236, p<0.001$; one-way ANOVA) (Fig. 3e, f). In contrast to the LC, no significant change of TH mRNA levels was observed in the SN following acute stress $(n=4, F(3,12)=1.126, p=$ 0.377; one-way ANOVA) (Fig. 3e, f). These results demonstrated the activation of noradrenergic neurons in the LC following the acute stress in Fischer rats.

\section{ARs in the brain}

Although both $\beta$-ARs ( $\beta 1$-AR, $\beta 2$-AR, and $\beta 3$-AR) and $\alpha$ ARs ( $\alpha 1-\mathrm{AR}$ and $\alpha 2-\mathrm{AR})$ are expressed in cultured microglia, the former has been well demonstrated to induce cAMP elevation $[41,47,61]$. We therefore investigated the expression and distribution of $\beta$-ARs in the brain.

RT-PCR analysis showed a clear band of $\beta 1-A R$ and $\beta 2-\mathrm{AR}$ in each brain region, including the $\mathrm{HC}, \mathrm{TM}$, and 


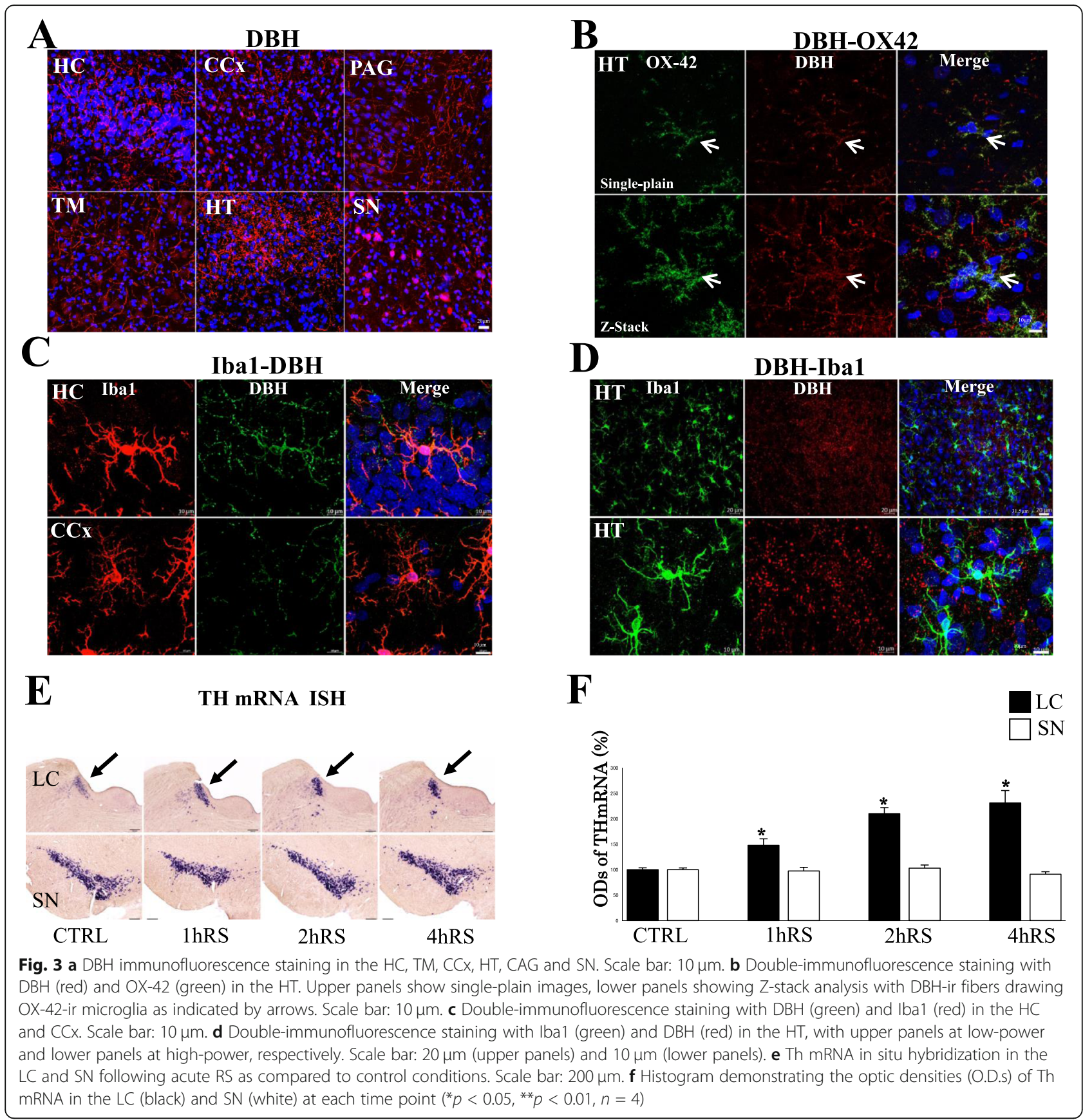

HT. However, $\beta 3$-AR was not detected in any brain region (Fig. 4a). ISH showed the expression of $\beta 1-A R$ and $\beta 2-A R$, but not $\beta 3-A R$, in the HT (Fig. $4 b$ ), which was further confirmed by IHC, showing the existence of $\beta 1$ AR and $32-A R$ in glia-like cells (Fig. 4b).

Laser scanning microscopy showed that no immunoreactive $\beta 3$-AR cells were co-localized with microglia (Fig. 4c) or astrocytes (Fig. 4d). In contrast, $\beta 1-A R$ and $\beta 2-A R$ were co-localized with microglia (Fig. 4c) and astrocytes (Fig. 4d).
$\beta$-Blockers significantly suppress Iba1-ir microglia

In order to study the functional involvement of $\beta$ ARs, the $\beta$-blocker propranolol $(10 \mathrm{mg} / \mathrm{kg})$ was administered intraperitoneally $1 \mathrm{~h}$ before each stress procedure (Fig. 5a) [72]. Corticosterone levels significantly increased during exposure to stress $(n=4$, $F(3,31)=27.401, p<0.001$; two-way ANOVA), and no significant effect of drug treatment was observed $(n=4, F(1,31)=0.575, p=0.456$; two-way ANOVA $)$ (Fig. 5b). 


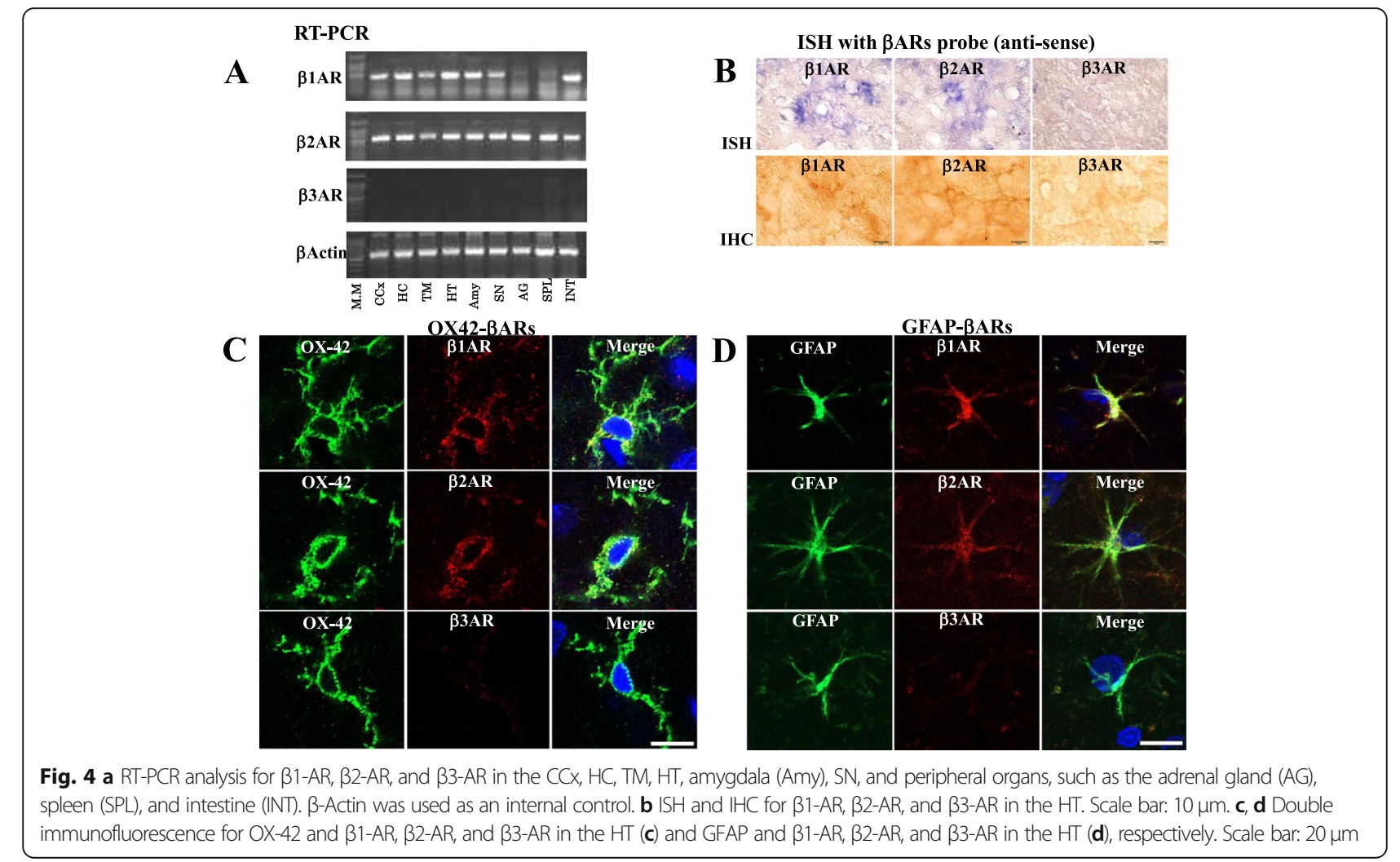

Furthermore, we evaluated cells morphology by employing parameters such as cell size, cell count, and intersections. In contrast to saline-treated rats, the microglial density looked sparse in the HT of propranolol-treated rats (Fig. 6A, B). The morphological activation of microglia differed significantly between saline- and propranolol-treated rats $(n=4, F(1,31)=$ $193.082, p<0.001$; two-way ANOVA). Propranolol significantly suppressed the microglial density at CTRL ( $n$ $=4, p<0.01), 1 \mathrm{~h} \mathrm{RS}(n=4, p<0.01), 2 \mathrm{~h} \mathrm{RS}(n=4, p<$ $0.01)$, and 4 h RS ( $n=4, p<0.01)$, compared with saline-treated rats (Fig. 7a). In addition, there was a significant effect of propranolol on the number of microglia $(n=4, F(1,31)=374.025, p=0.001$; twoway ANOVA) in that the HT of propranolol-treated rats had a significantly lower microglial count at CTRL $(n=4, p<0.01), 1$ h RS $(n=4, p<0.01), 2 \mathrm{~h}$ RS $(n=4, p<0.01)$, and $4 \mathrm{~h} \operatorname{RS}(n=4, p<0.01)$ than that of saline-treated rats (Fig. 7a). There was no significant effect of propranolol treatment on astrocyte cell size $(n=4, F(1,31)=0.060, p=0.809$; two-way ANOVA) or cell count $(n=4, F(1,31)=$ 0.053, $p=0.819$; two-way ANOVA) (Fig. 7b)

Moreover, we analyzed morphological changes with Sholl analysis. As shown in Fig. 8a, there was some difference on the count of intersections between 10 and
$20 \mu \mathrm{m}$ on the distance from soma. For instance, at $10 \mu \mathrm{m}$ from soma, there was no difference on the intersection numbers in the control conditions between saline and $\beta$-blocker treatment. In the stressed conditions, such as $1 \mathrm{~h}$ RS or $2 \mathrm{~h}$ RS, there was decrease on the intersection numbers both in saline and $\beta$-blockertreated rats. At $20 \mu \mathrm{m}$ from soma, there were significant differences both in control and stressed conditions between saline and $\beta$-blocker treatment. In particular, in saline-treated rats, there was a significant decrease of the count of intersections on microglial cells in stressed conditions $(n=4, F(3,12)=18.000, p<0.001$; one-way ANOVA). However, in propranolol-treated rats, there was no significant change between control and stressed conditions in propranolol-treated rats based on Sholl analysis $(n=4, F(3,12)=0.425, p=0.739$; one-way ANOVA) (Fig. 8a, c). In fact, there was already a significant decrease of intersection counts even in control conditions (Fig. 8c). The decrease of intersections of microglia in control conditions in propranolol treatment is likely to be due to cellular shrinkage as shown in Fig. 6B, not to the hypertrophic changes.

With regard to astrocytes, there was no significant effect of stress $(n=4, F(3,12)=0.284, p=0.836$; one-way ANOVA $)$ or propranolol $(n=4, F(3,12)=0.393, p=$ 0.760; one-way ANOVA) on the intersections of GFAP- 


\section{Experimental Protocol}

A

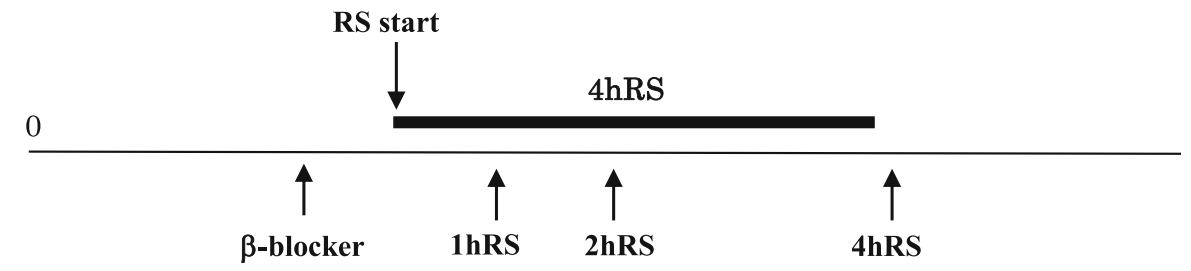

B Corticosterone (CORT) measurement

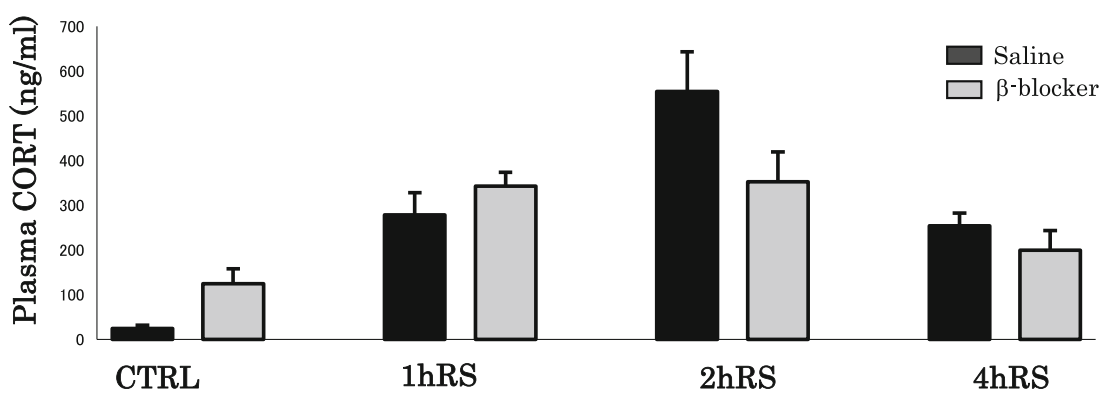

Fig. 5 a A schematic depiction of the $\beta$-blocker treatment protocol. b Plasma corticosterone levels $(\mathrm{ng} / \mathrm{mL})$ of saline- and $\beta$-blocker-treated rats in acute RS. Results are presented as means \pm SEM

ir astrocytes (Fig. 8b, d). There were also no significant effects of stress or propranolol in the HC, TM, and SN (data not shown).

Curiously, during the course of the experiment we found that there are two types of microglia: OX- $42^{+}$$\mathrm{Iba}^{+}$and $\mathrm{OX}-42^{+}-\mathrm{Iba1}^{-}$(Fig. 6D). As to the cause behind the drastic decrease of Iba1-ir microglial cells following propranolol, we found no evidence of cleaved caspase-3 staining (6E), suggesting that the change may be not through apoptosis.

Next, we quantified the proinflammatory markers IL-1 $\beta$ and IL-18 using real-time PCR and found that propranolol significantly suppressed the expression of IL-1 $\beta$ and IL-18 mRNA at CTRL $(n=4, p<0.01), 1$ h RS $(n=4, p<0.01), 2$ h RS $(n=4, p<0.05)$, and 4 h RS $(n=4, p<0.05)$, as compared to saline-treated rats (Fig. 7c).

\section{a-Blockers significantly increase Iba1-ir microglia}

In order to study the functional involvement of $\alpha$ ARs, the $\alpha 1$-AR blocker prazosin $(0.5 \mathrm{mg} / \mathrm{kg})$ [32] and the $\alpha 2$-AR blocker yohimbine $(3.0 \mathrm{mg} / \mathrm{kg})$ [61] were administered intraperitoneally $1 \mathrm{~h}$ before each stress procedure (Fig. 9a).
The levels of corticosterone after saline, prazosin, and yohimbine treatment did not increase significantly with stress exposure $(n=4, F(3,47)=1.311, p=0.286$; two-way ANOVA) (Fig. 9b). However, a significant difference in the corticosterone levels was found among saline- and $\alpha$ blocker-treated rats under control conditions $(n=4, F(2$, $47)=22.303, p<0.001$; two-way ANOVA) (Fig. 9b).

Microglia were significantly activated in $\alpha$-blockertreated rats $(n=4, F(3,47)=10.447, p<0.001$; two-way ANOVA), and the morphological activation of saline-, prazosin-, and yohimbine-treated rats differed significantly $(n=4, F(2,47)=7.638, p<0.001$; two-way ANOVA). In prazosin-treated rats, microglial activation occurred in a similar pattern to that in saline-treated rats based on cell size and dendrite intersections (Fig. 10A-D). In contrast, microglial activation was detected even under control conditions, occurring more clearly in yohimbine-treated rats than in prazosin-treated rats, following RS (Fig. 10A-D). In addition, the microglial cell count increased significantly with time $(n=4, F(3,47)=4.138, p<0.05$; twoway ANOVA), differing significantly among groups $(n=4$, $F(2,47)=24.203, p<0.001$; two-way ANOVA) (Fig. 10E). These results suggest that $\alpha 2$-AR blockade with yohimbine facilitated microglial activation. 

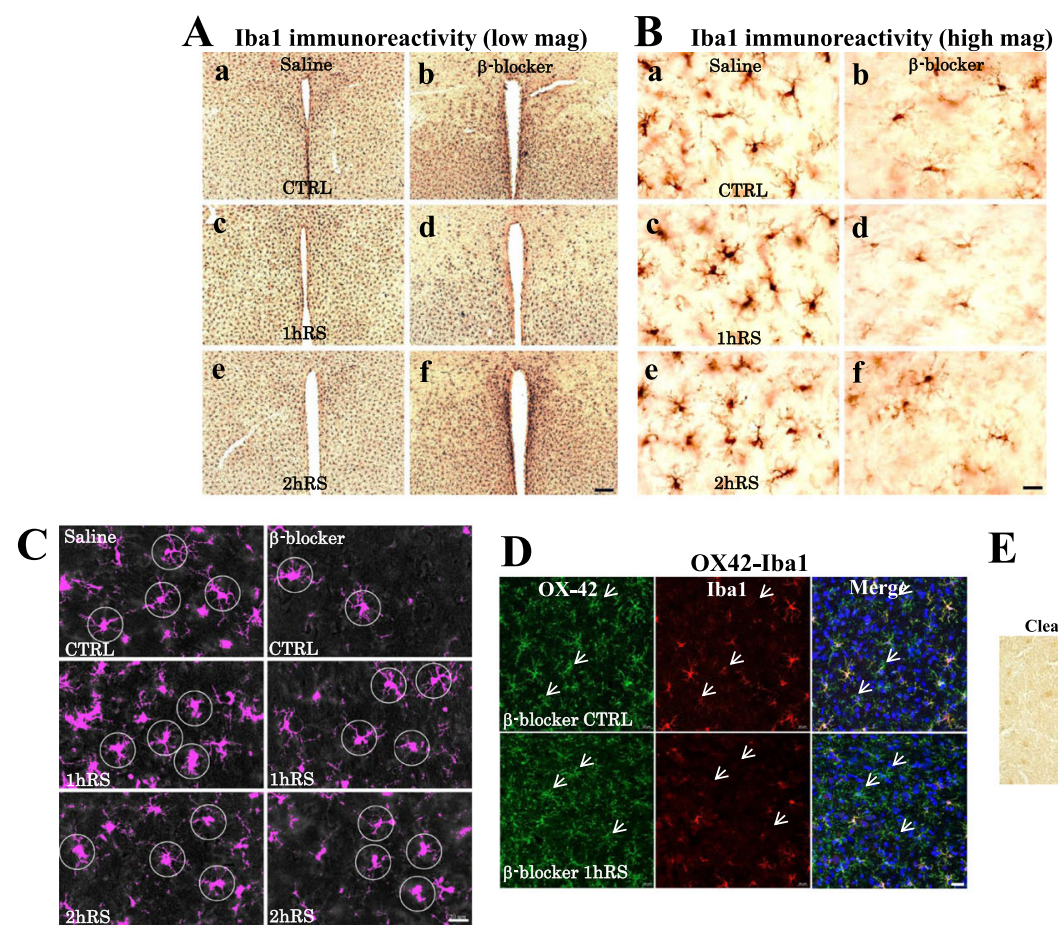

$\mathbf{E}$

Fig. 6 A Iba1 IHC for CTRL (a, b), 1 h RS (c, d), and $2 \mathrm{~h}$ RS (e, f) after saline and $\beta$-blocker treatment, respectively. B High-power photomicrographs of Iba1 IHC for CTRL (a, b), 1 h RS (c, d), and $2 \mathrm{~h}$ RS (e, f) after saline and $\beta$-blocker treatment, respectively. Scale bar: $200 \mu \mathrm{m}$ in low-power and $20 \mu \mathrm{m}$ in high-power photos. C Circles, $20 \mu \mathrm{m}$ from the soma, used for Scholl analysis are shown on Iba1-ir microglia at CTRL, $1 \mathrm{~h} \mathrm{RS}$, and $2 \mathrm{~h}$ RS after saline and $\beta$-blocker treatment, respectively. Scale bar: $20 \mu \mathrm{m}$. D Double-immunofluorescence staining with OX-42 (green) and Iba1 (red) in the HT, with upper panes at CTRL ( $\beta$-blocker), and 1h RS ( $\beta$-blocker), respectively. Scale bar: $20 \mu \mathrm{m}$. E No immunoreactivity to cleaved caspase-3 was found in the HT at $1 \mathrm{~h}$ RS after propranolol treatment. Scale Bar: $20 \mu \mathrm{m}$

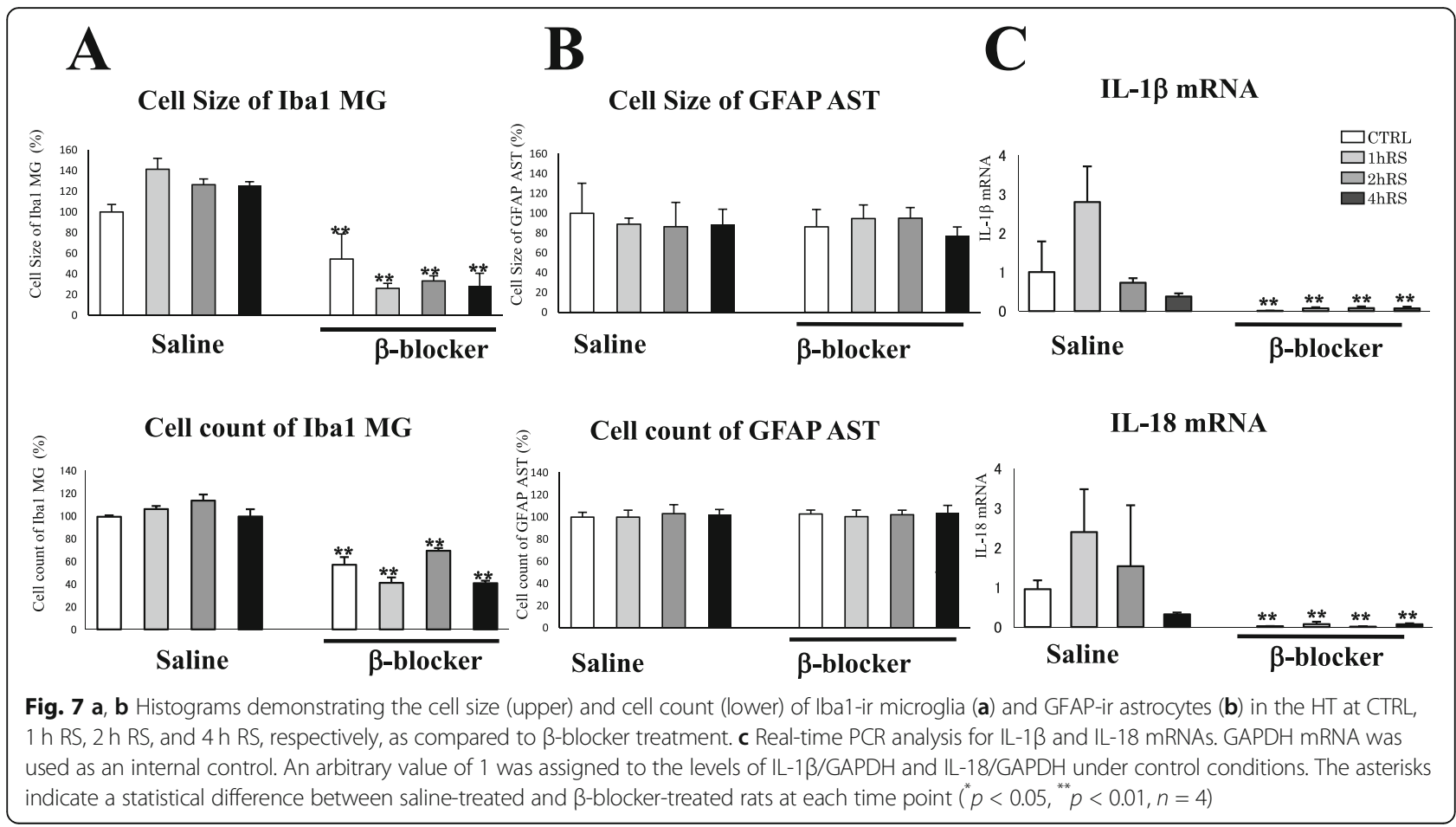




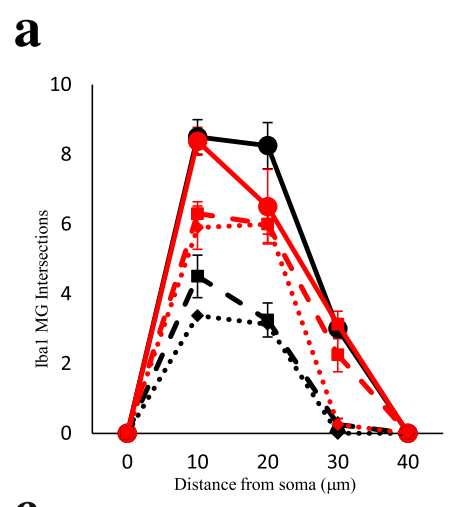

c

Iba1 MG Intersections

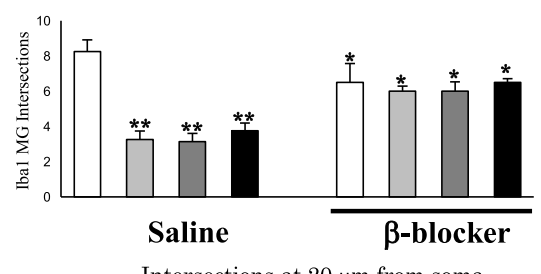

b

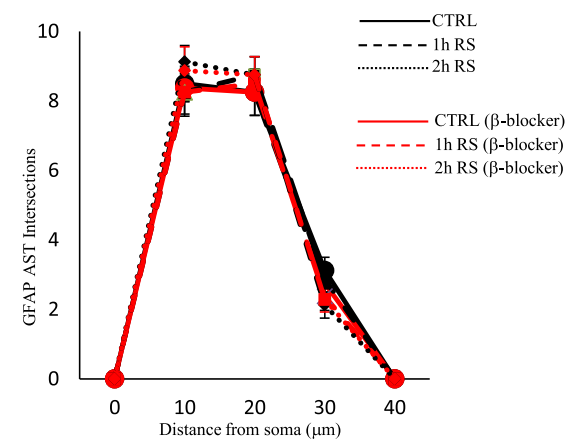

d

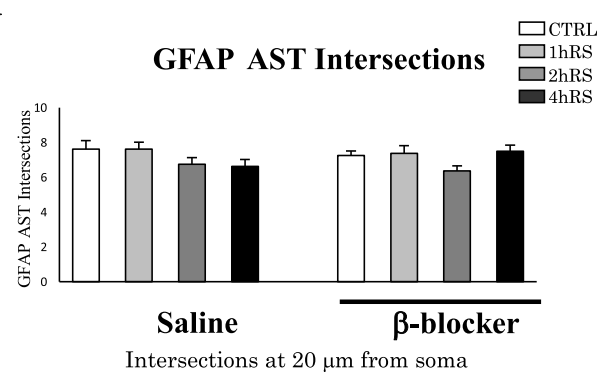

Fig. 8 a, b Scholl analysis of microglia and astrocytes in the HT at CTRL, 1 h RS, and $2 \mathrm{~h}$ RS, respectively, as compared to $\beta$-blocker treatment. $\mathbf{c}$, $\mathbf{d}$ Histograms demonstrating the intersections count of Iba1-ir microglia (c) and GFAP-ir astrocytes (d) at the distance of $20 \mu \mathrm{m}$ from soma. The asterisks indicate a statistical difference between saline-treated and $\beta$-blocker-treated rats at each time point $\left({ }^{*} p<0.05,{ }^{* *} p<0.01, n=4\right)$

\section{Comparison of stress-induced microglial activation between wild-type (WT) and $\beta 1-A R$ and $\beta 2-A R$ double- knockout (DKO) mice}

Lastly, we compared acute stress-induced microglial activation between WT and DKO mice lacking $\beta 1-\mathrm{AR}$ and $\beta 2$-AR (Fig. 11a).

Corticosterone levels increased significantly upon exposure to acute RS $(n=4, F(2,23)=20.382, p<0.001$; two-way ANOVA), with no significant difference between WT and DKO mice $(n=4, F(1,23)=2.670, p=0.120$; two-way ANOVA) (Fig. 11b).

Under control conditions, the microglia maintained a resting morphology with small cell somas and thin processes in both WT and DKO mice (Fig. 12A). In WT mice, a single 2-h session transformed resting microglia into activated microglia, presenting enlarged cell somas and thick processes, in the $\mathrm{HT}(n=4, p<0.01), \mathrm{HC}(n=4, p<0.01)$, and TM $(n=4, p<0.01)$ (Fig. 12B). In contrast, in DKO mice, a single 2 -h session failed to show microglial activation in the HT, TM, and HC (Fig. 12B). Two-way ANOVA based on cell size revealed that the stress-induced microglial activation was significantly inhibited in the DKO mice in the HT $(n=4, F(1,15)=221.618, p<0.001)$, TM $(n=4$, $F(1,15)=108.529, p<0.001)$, and $\mathrm{HC}(n=4, F(1,15)=$ 108.315, $p<0.001$ ) (Fig. 12B).

In WT mice, $\beta$-blocker treatment significantly inhibited the morphological microglial activation in the HT $(n=4, p<0.01), \mathrm{TM}(n=4, p<0.01)$, and $\mathrm{HC}(n=4$, $p<0.01$ ) (Fig. 12B).

\section{Discussion}

The main finding of the present study was that microglial activation, as represented by enlarged Iba1-ir cell surface areas in the HT, HC, and TM, was significantly inhibited by pretreatment with the $\beta$-blocker propranolol. This finding was further confirmed by impaired, stress-induced, microglial activation in DKO mice, which contrasted sharply with that of WT mice.

Regarding the mechanism of neuronal-glial interaction, we demonstrated that fibers immunoreactive to $\mathrm{DBH}$ extend into wide brain regions, including the $\mathrm{HC}$, TM, and HT. This result is consistent with those of previous studies which demonstrated extensive branched axons providing the main source of NA throughout the brain including neocortex, amygdala, cerebellum and spinal cord $[37,40]$. In addition to a variety of neuropeptides including neuropeptide $\mathrm{Y}$, somatostatin, cholecystokinin, and galanin, the LC contains two enzymes, $\mathrm{DBH}$ and $\mathrm{TH}$, which are critically involved in NA biosynthesis $[5,51]$. Therefore, it is crucial to know how $\mathrm{DBH}$ and $\mathrm{TH}$ respond to the acute RS. Importantly, we found the density of DBH-ir neurons in the LC increased significantly after $2 \mathrm{~h}$ RS (data not shown). In addition, mRNA of $\mathrm{TH}$ was shown to significantly 


\section{A Experimental Protocol}

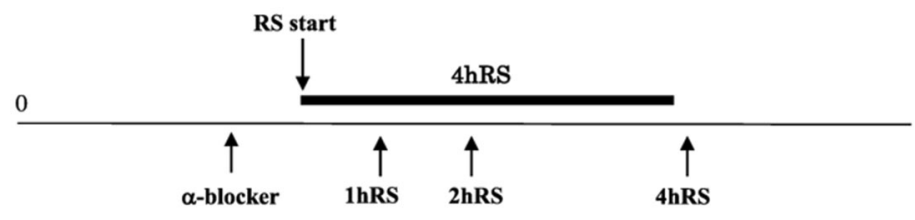

B Corticosterone (CORT) measurement

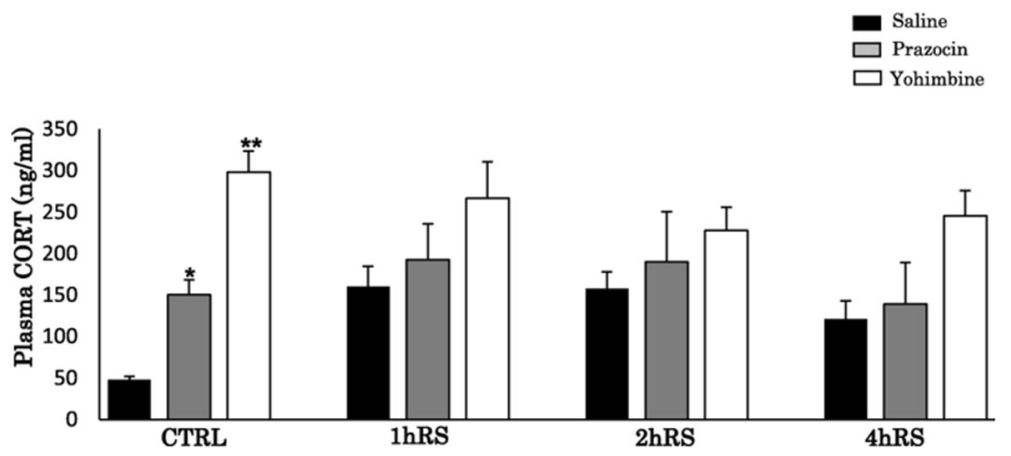

Fig. 9 a A schematic depiction of the a-blocker treatment protocol with prazosin and yohimbine. b Plasma corticosterone levels (ng/mL) of saline- and a-blocker-treated rats in acute RS. The asterisks indicate a statistical difference between saline- and yohimbine-treated rats following acute RS at each time point $\left({ }^{*} p<0.05,{ }^{* *} p<0.01, n=4\right)$. Results are presented as means \pm SEM

increase following the RS only in the LC. Thus, these results suggest the activation of the noradrenergic neurons. On the other hand, it has been reported that microglial cells possess receptors for NA, such as $\beta 1-\mathrm{AR}$, $\beta 2$-AR, $\beta 3$-AR, $\alpha 1$-AR, and $\alpha 2-A R[41,61,72]$. In the present study, confocal microscopic Z-stack analysis revealed that $\mathrm{DBH}$-ir fibers edged microglial cells. In previous reports based on electron microscopy, it has been reported that noradrenergic synapses release NA into the extracellular fluid, diffusing the neurotransmitter into the surrounding synaptic clefts $[2,3]$. Moreover, confocal microscopy showed that both $\beta 1$-AR and $\beta 2$ $A R$, but not $\beta 3-A R$, were co-localized with $O X-42$-ir microglia in the brain. Taken together, these results suggest that microglial cells possessing $\beta 1$-AR and $\beta 2$ AR may receive adrenergic signals from noradrenergic neurons.

In the present study, we investigated the role of $\beta$-ARs using the $\beta$-blocker propranolol prior to acute RS and observed that microglial activation triggered by acute RS was substantially inhibited in the HT, HC, and TM. In addition, pretreatment with propranolol significantly decreased the number of Iba1-ir microglial cells in those regions. These findings are consistent with those of previous studies demonstrating that propranolol inhibits microglial activation following various stresses, such as social disruption stress [72] and inescapable foot shock
[30]. It was also reported that the stress-associated increase of IL-1 $\beta$ mRNA is inhibited by propranolol in the central nervous system [8]. Therefore, we suggest that stress-induced microglial activation may occur through $\beta$-ARs.

On the other hand, and against our expectations, microglia were further activated by pretreatment with the $\alpha 2$-AR blocker yohimbine. This effect was stronger than that of the $\alpha 1-A R$ blocker prazosin. In this study, it was also found that the levels of plasma corticosterone were elevated in animals treated with those $\alpha$-AR blockers, which supports the fact that the hypothalamic pituitary adrenal (HPA) axis may be activated by pretreatment with $\alpha$-AR blockers. In fact, this finding is consistent with those of previous studies showing upregulated corticosterone levels in prazosin- or yohimbinetreated rats [38, 55]. Importantly, the LC receives afferent neurons from the HT [5], causing NA to increase through the activated HPA axis. In addition, $\alpha 2$-AR blockade in chronic, unexpected, mild stress increases the level of NA in the brain [70]. It is well established that the $\alpha 2$-AR plays a role as a presynaptic inhibitory receptor regulating neurotransmitters' release $[1,12,22]$. Therefore, it is possible that the enhanced microglial activation by yohimbine treatment may be induced by the increased release of NA from the synaptic terminals. The results obtained with $\alpha$-blockers, such as 


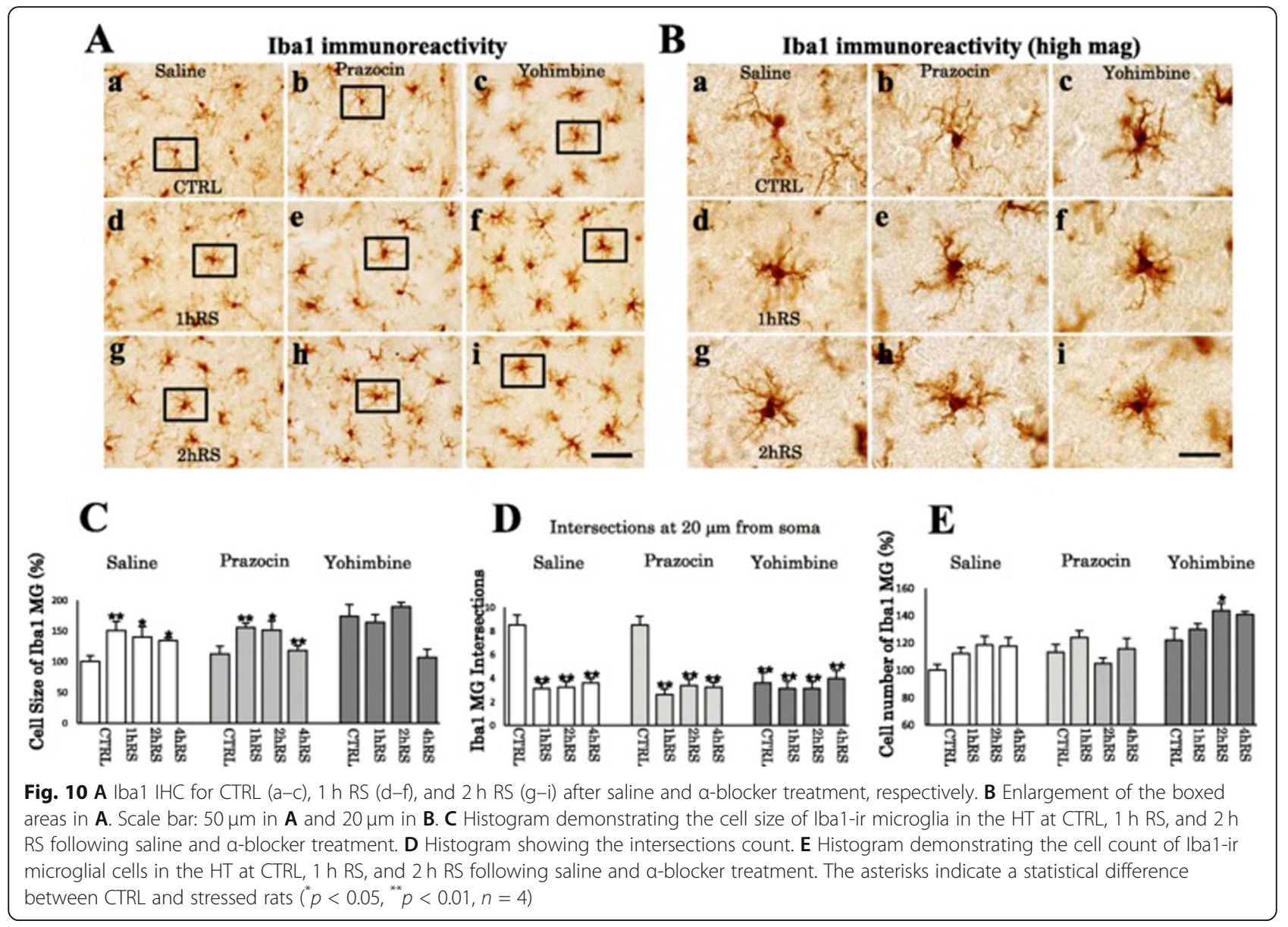

\section{A Experimental Protocol}

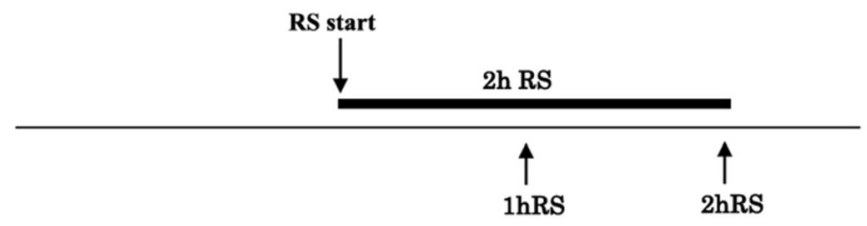

B Corticosterone (CORT) measurement

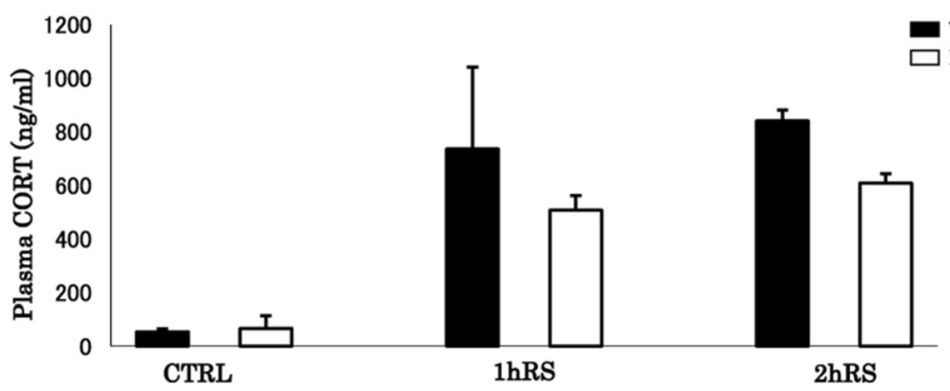

Fig. 11 a A schematic depiction of the stress protocol for WT and DKO mice. b Plasma corticosterone levels (ng/mL) of WT and DKO mice following acute RS $(n=4)$. Data are presented as means \pm SEM 


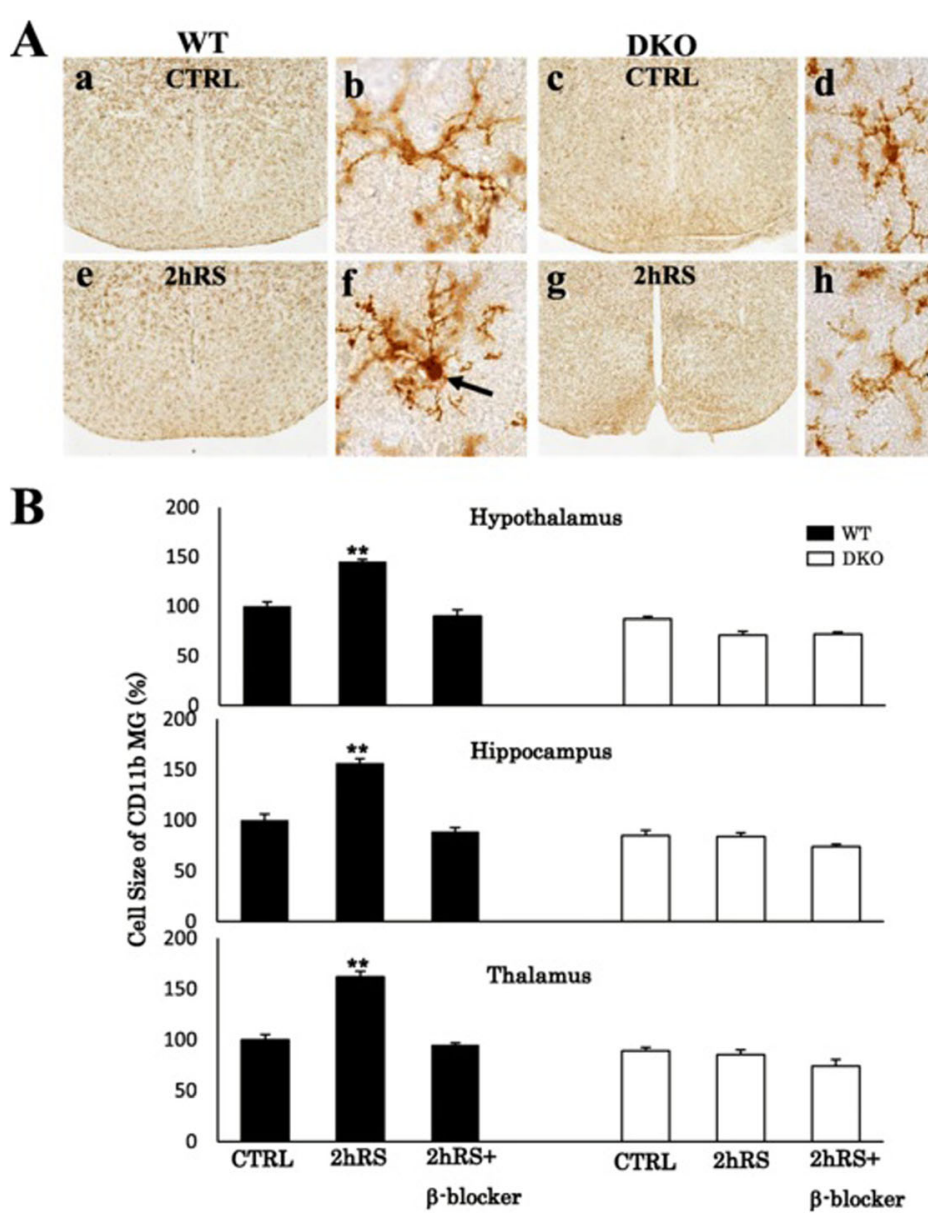

Fig. 12 A CD11b IHC for CTRL in WT (a) and DKO (c) mice and for $2 \mathrm{~h}$ RS in WT (e) and DKO (f) mice in low-power photographs and for CTRL in WT (b) and DKO (d) mice and for $2 \mathrm{~h}$ RS in WT (f) and DKO (h) mice in high-power photographs. Scale bar: $500 \mu \mathrm{m}$ in low-power and $20 \mu \mathrm{m}$ in high-power photos. B Histograms demonstrating the cell size of CD11b-immunoreactive microglia of WT and DKO mice in the HT, HC, and TM following acute $2 \mathrm{~h} \mathrm{RS}$ and $2 \mathrm{~h}$ RS with $\beta$-blocker treatment. The asterisks indicate the statistical difference between acute RS rats and control rats $\left({ }^{*} p<0.01, n=4\right)$

prazosin and yohimbine, further suggest that stressinduced microglial activation may be achieved through NA upregulation.

Although the involvement of $\alpha$-ARs in stress-induced microglial activation cannot be excluded, the effect of propranolol, a $\beta 1$-AR and $\beta 2$-AR blocker, was more predominant than those of blockers for $\alpha 1-\mathrm{AR}$ and $\alpha 2-\mathrm{AR}$. Therefore, we used DKO mice lacking $\beta 1$-AR and $\beta 2$ $A R$ in order to study the functional involvement of $\beta 1$ $A R$ and $\beta 2-A R$ in microglial activation. Microglial activation was first confirmed in WT mice exposed to $2 \mathrm{~h}$ RS. IHC demonstrated that, in DKO mice, the intensities of CD11b immunoreactivities, as a marker of morphological microglial activation in mice, were significantly suppressed in the HT, HC, and TM following acute RS. The level of corticosterone was relatively decreased in DKO mice, as compared to WT mice. Since corticosterone limits microglial activation [58], it is unlikely that the microglial suppression observed in DKO mice may have derived from the corticosterone levels. In addition, the stress-induced microglial activation observed in WT mice was significantly suppressed by propranolol. Intriguingly, there was no significant change in microglial morphology between WT and DKO mice under control conditions, suggesting that $\beta$-ARs may not be involved in regulation of resting microglia. As a whole, the present study demonstrates that deletion of $\beta 1$-AR and $\beta 2-A R$ genes substantially suppresses acute stressinduced microglial activation in the brain. Thus, $\beta 1$-AR and $\beta 2$-AR may directly transmit signals, presumably NA, resulting in stress-induced microglial activation.

In several studies, the anti-inflammatory effects of NA have been reported, which contradicts the results of our study. For instance, in cultured microglia, NA and isoproterenol, a $\beta$-AR agonist, inhibit proinflammatory markers, such as IL-1 $\beta$, IL-6, and iNOS mRNA, following 
LPS treatment $(1.0 \mu \mathrm{g} / \mathrm{mL})$, through the inhibition of NF$\kappa \mathrm{B}$ translocation [27]. In addition, NA depletion in aged rats' $\mathrm{HC}$ has been found to aggravate inflammation following LPS treatment $(0.75 \mathrm{mg} / \mathrm{kg})$ [6], whereas the proinflammatory effects of NA have been demonstrated in several studies. For instance, in cultured microglia, administering isoproterenol significantly increases the induction of IL-1 $\beta$ mRNA [64]. $\beta 2$-AR stimulation leads to an increase of IL-1 $\beta$ and IL-6 [60]. These anti- and proinflammatory effects of NA comprise an intriguing paradox. One aspect common to the abovementioned studies is that experiments showing an anti-inflammatory effect of NA are mostly conducted in combination with LPS treatment, which induces NF- $\mathrm{kB}$ translocation into the nucleus. Unlike those experiments, we did not use LPS in the present study. Considering the existence of an alternative mechanism to the conventional PKA/NF- $\mathrm{BB}$ dependent pathway [47], such differential pathway might contribute to the differential effects of NA. It is conceivable that such alternative pathway may underlie the proinflammatory effects of NA.

Microglia play distinctive roles depending on their morphologies. Under resting conditions, microglia with ramified, long, thin processes play constructive roles, such as debris clearance, neuronal support, and synaptic monitoring and remodeling $[14,15]$. In contrast, under morphological activation, microglia become hypertrophic with short and thick processes and play various harmful roles, such as cytokine and superoxide release, neurotoxicity, and phenotypic polarization $[10,18,36]$. It is, therefore, critical to keep microglia quiescent and at a resting condition throughout the brain. Importantly, the $\beta$-blocker propranolol has been shown to effectively ameliorate neurodegenerative disorders, such as $\mathrm{AD}$ and PD. In particular, propranolol $(5 \mathrm{mg} / \mathrm{kg}$ ) has been shown to reduce cognitive deficits and amyloid and tau pathology in a model of AD [16]. In addition, microglial inhibition during sleep is reported to be critical for preventing cognitive dysfunction, via clearance of metabolic waste $[4,24-26,43,73]$. Furthermore, $\beta$-blockers are reported to prevent anxiety-like behaviors through microglial inhibition [72]. Intriguingly, microglial inhibition by minocycline was found to lead to emotional stability [31]. Thus, controlling the microglial status may contribute to a variety of brain functions, ranging from cognition to mental activity. We therefore suggest that $\beta$-blockers, rather than $\alpha$-blockers, are critical for maintaining the microglial status.

\section{Conclusions}

In the present study, we demonstrated that neurons/ microglia may interact with NA throughout the brain via $\beta 1-A R$ and $\beta 2-A R$. NA may therefore be one of the neurotransmitters regulating microglial activation in the brain. $\beta$-blockers may effectively treat neurological disorders associated with microglial activation.

\section{Abbreviations}

AD: Alzheimer's disease; ANOVA: Analysis of variance; AR: Adrenergic receptor; CORT: Corticosterone; CTRL: Control; DBH: Dopamine beta hydroxylase; DG: Dentate gyrus; DKO: Double-knockout mouse; ELISA: Enzyme-linked immunosorbent assay; HC: Hippocampus; HPA: Hypothalamic pituitary adrenal axis; HT: Hypothalamus; IHC: Immunohistochemistry; ISH: In situ hybridization; LC: Locus ceruleus; LPS: Lipopolysaccharide; NA: Noradrenaline; OD: Optic density;

PD: Parkinson's disease; RS: Restraint stress; SN: Substantia nigra; TH: Tyrosine hydroxylase; TM: Thalamus; WT: Wild-type mouse

\section{Acknowledgements}

The authors thank Dr. Kenji Suzuki for kindly providing antibodies (Ki67), Mrs. Shino Oikawa and Ms. Yuko Kai for supporting the ELISA analysis of this work, and all of them, belonging to the department of physiology at Nippon Medical School, for their support of this work.

\section{Authors' contributions}

SS performed animal experiments, immunohistochemistry, in situ hybridization, PCR, ELISA; analyzed and interpreted data; and contributed to the writing of the manuscript. $\Pi, \mathrm{MH}, \mathrm{HO}$, and $\mathrm{YT}$ contributed to the design of the experiments and analyzed the data. YK contributed to experimental design and helped with writing. All authors read and approved the final manuscript.

\section{Funding}

This study was supported by JSPS KAKENHI grant number 24500465 (SS) from the Ministry of Education, Culture, Sports, Science, and Technology of Japan.

\section{Availability of data and materials}

All data generated or analyzed during this study are included in this work.

Ethics approval and consent to participate

All animal studies were approved by the Institutional Animal Care and Use Committee of the Nippon Medical School.

\section{Consent for publication}

Not applicable

\section{Competing interests}

The authors declare that they have no competing interests.

\section{Author details}

1Department of Physiology, Nippon Medical School, 1-1-5 Sendagi Bunkyo-ku, Tokyo 113-8602, Japan. ${ }^{2}$ Institute of Agrobiological Sciences, National Agriculture and Food Research Organization, 1-2 Ohwashi, Tsukuba, Ibaraki 305-8634, Japan. ${ }^{3}$ Division of Sensory and Motor Systems, Tokyo Metropolitan Institute of Medical Science, 2-1-6 Kamikitazawa, Setagaya-ku, Tokyo 156-0057, Japan.

Received: 17 March 2019 Accepted: 6 November 2019

Published online: 17 December 2019

\section{References}

1. Altman JD, Trendelenburg AU, McMillan L, Bernstein D, Limbird I, Starke K, Kobilka BK, Hein L. Abnormal regulation of the sympathetic nervous system in a2A-adrenergic receptor knockout mice. Mol Pharmacol. 1999;56:154-61.

2. Aoki C. Beta-adrenergic receptors: astrocytic localization in the adult visual cortex and their relation to catecholamine axon terminals as revealed by electron microscopic immunocytochemistry. J Neurosci. 1992;12:781-92.

3. Aoki C, Pickel VM. Ultrastructural relations between $\beta$-adrenergic receptors and Catecholaminergic neurons. Brain Res Bull. 1992;29:257-63.

4. Bellesi M, de Vivo L, Chini M, Gilli F, Tononi G, Cirelli C. Sleep loss promotes astrocytic phagocytosis and microglial activation in mouse cerebral cortex. J Neurosci. 2017:37:5263-73.

5. Benarroch EE. Locus coeruleus. Cell Tissue Res. 2017;373:221-32. 
6. Bharani K, Derex R, Granholm A, Ledreux A. A noradrenergic lesion aggravates the effects of systemic inflammation on the hippocampus of aged rats. PLoS One. 2017;12:e0189821.

7. Bhat SA, Goel R, Shukla S, Shukla R, Hanif K. Angiotensin receptor blockade by inhibiting glial activation promotes hippocampal neurogenesis via activation of Wnt/b-catenin signaling in hypertension. Mol Neurobiol. 2017; 55:5282-98.

8. Blandino P Jr, Barnum CJ, Deak T. The involvement of norepinephrine and microglia in hypothalamic and splenic IL-1beta responses to stress. $J$ Neuroimmunol. 2006:173:87-95.

9. Blandino P Jr, Barnum CJ, Solomon LG, Larish Y, Lankow BS, Deak T. Gene expression changes in the hypothalamus provide evidence for regionallyselective changes in IL-1 and microglial markers after acute stress. Brain Behav Immun. 2009;23:958-68.

10. Block ML, Hong JS. Microglia and inflammation-mediated neurodegeneration: Multiple triggers with a common mechanism. Prog Neurobiol. 2005;76:77-98.

11. Bollinger JT, Bergeon Burns CM, Wellman CL. Differential effects of stress on microglial cell activation in male and female medial prefrontal cortex. Brain Behav Immun. 2016;52:88-97.

12. Bücheler MM, Hadamek $K$, Hein L. Two a-adrenergic receptor subtypes, a2A and a2C, inhibit transmitter release in the brain of gene-targeted mice. Neuroscience. 2002;109:819-26.

13. Cronk JC, Filiano AJ, Louveau A, Marin I, Marsh R, Ji E, Goldman DH, Smirnov I, Geraci N, Acton S, Overall CC, Kipnis J. Peripherally derived macrophages can engraft the brain independent of irradiation and maintain an identity distinct from microglia. J Exp Med. 2018;215:1627-47.

14. Dá Mesquita S, Ferreira AC, Sousa JC, Correia-Neves M, Sousa N, Marques F. Insights on the pathophysiology of Alzheimer's disease: the crosstalk between amyloid pathology, neuroinflammation and the peripheral immune system. Neurosci Biobehav Rev. 2016;68:547-62.

15. Di Benedetto S, Müller L, Wenger E, Düzel S, Pawelec G. Contribution of neuroinflammation and immunity to brain aging and the mitigating effects of physical and cognitive interventions. Neurosci Biobehav Rev. 2017;75:114-28.

16. Dobarro M, Gerenu G, Ramirez M. Propranolol reduces cognitive deficits, amloid and tau pathology in Alzheimer's transgenic mice. Int J Neuropsychopharmacol. 2013;16:2245-57.

17. Galvez R, Mesches MM, McGaugh JL. Norepinephrine release in the amygdala in response to footshock stimulation. Neurobiol Learn Mem. 1996;66:253-7.

18. Gao HM, Kotzbauer PT, Uryu K, Leight S, Trojanowski JQ, Lee VM. Neuroinflammation and oxidation/nitration of a-synuclein linked to dopaminergic neurodegeneration. J Neurosci. 2008;28:7687-98.

19. George R, Griffin JW. Delayed macrophage responses and myelin clearance during Wallerian degeneration in the central nervous system: the dorsal radiculotomy model. Exp Neurol. 1994;129:225-36.

20. Gibberd FB, Simmonds JP. Neurological disease in ex-Far-East prisoners of war. Lancet. 1980;2:135-7.

21. Graeber MB. Changing face of microglia. Science. 2010;330:783-8.

22. Gyires K, Zadori ZS, Török T, Matyus P. a-Adrenoceptor subtypes-mediated physiological, pharmacological actions. Neurochem Int. 2009;55:447-53.

23. Haarman BC, Riemersma-Van der Lek RF, de Groot JC, Ruhe HC, Klein HC, Zandstra TE, Burger H, Schoevers RA, de Vries EF, Drexhage HA, Nolen WA Doorduin J. Neuroinflammation in bipolar disorder-A [(11)C]-(R)-PK11195 positron emission tomography study. Brain Behav Immun. 2014;40:219-25.

24. He X, Liu D, Zhang Q, Liang F, Dai G, Zeng J, Pei Z, Xu G, Lan Y. Voluntary exercise promotes glymphatic clearance of amyloid beta and reduces the activation of astrocytes and microglia in aged mice. Front Mol Neurosci. 2017:10:144

25. Huang CT, Chiang RP, Chen C, Tsai Y. Sleep deprivation aggravates median verve injury-induced neuropathic pain and enhances microglial activation by suppressing melatonin secretion. Sleep. 2014;37:1513-23.

26. Iliff JJ, Wang M, Liao Y, Plogg BA, Peng W, Gundersen GA, Benveniste $H$, Vates GE, Deane R, Goldman SA, Nagelhuss EA, Nedergaard M. A paravascular pathway facilitates CSF flow through the brain parenchyma and the clearance of interstitial solutes, including amyloid $\beta$. Sci Transl Med. 2012:4:147ra111.

27. Ishii Y, Yamaizumi A, Kawakami A, Islam A, Choudhury ME, Takahashi H, Yano H, Tanaka J. Anti-inflammatory effects of noradrenaline on LPS-treated microglial cells: suppression of NFKB nuclear translocation and subsequent STAT1 phosphhorylation. Neurochem Int. 2015;90:56-66.
28. Iwasaki-Sekino A, Mano-Otagiri A, Ohata H, Yamauchi N, Shibasaki T. Gender differences in corticotropin and corticosterone secretion and corticotropinrelasing factor mRNA expression in the paraventricular nucleus of the hypothalamus and the central nucleus of the amygdala in response to footshock stress or psychological stress in rats. Psychoneuroendocrinology. 2009;34:226-37.

29. Jezova D, Ochedalski T, Glickman M, Kiss A, Aguilera G. Central corticotropin-releasing hormone receptors modulate hypothalamicpituitary-adrenocortical and sympathoadrenal activity during stress. Neuroscience. 1999;3:797-802.

30. Johnson JD, Campisi J, Sharkey CM, Kennedy SL, Nickerson M, Greenwood BN, Fleshner M. Catecholamines mediate stress-induced increases in peripheral and central inflammatory cytokines. Neuroscience. 2005;135:1295-307.

31. Kato T, Ohgidani M, Watabe M, Kanba S. Translational research to clarify the microglia hypothesis of the mind. Jpn J Biol Psychiatry. 2016;27:207.

32. Kikuchi-Utsumi K, Ishizaka M, Matsumura N, Watabe M, Aoyama K, Sasakawa $\mathrm{N}$, Nakaki T. Involvement of the a1D-adrenergic receptor in methamphetamine-induced hyperthermia and neurotoxicity in rats. Neurotox Res. 2013;24:130-8.

33. Kojo A, Yamada K, Kubo K, Yamashita A, Yamamoto T. Occlusal disharmony in mice transiently activates microglia in hippocampal CA1 region but not in dentate tyrus. Tohoku J Exp Med. 2010;221:237-43.

34. Kreutzberg GW. Microglia: a sensor for pathological events in the CNS. Trends Neurosci. 1996;19:312-8.

35. Lehmann M, Cooper HA, Maric D, Herkenham M. Social defeat induces depressive-like states and microglial activation without involvement of peripheral macrophages. J Neuroinflammation. 2016;13:224.

36. Lenz KM, Nugent BM, Haliyur R, McCarthy MM. Microglia are essential to masculinization of brain and behavior. J Neurosci. 2013;33:2761-72.

37. Lindvall $\mathrm{O}$, Bjorklund $\mathrm{A}$. The organization of the ascending catecholamine neuron systems in the rat brain as revealed by the glyoxylic acid fluorescence method. Acta Physiol Scand Suppl. 1974;412:1-48.

38. Martinez-Pinero M, Milanes MV, Alcaraz C, Vargas ML. Catecholaminergic mediation of morphine-induced activation of pituitary-adrenocortical axis in the rat: implication of $\alpha$ - and $\beta$-adrenoceptors. Brain Res. 1994;668:122-8

39. McEwen BS, Magarinos AM. Stress effects on morphology and function of the hippocampus. Ann N Y Acad Sci. 1997;821:271-84.

40. Mello CV, Pinaud R, Ribeiro S. Noradrenergic system of the zebra finch brain: immunocytochemical study of dopamine-b-hydroxylase. J Comp Neurol. 1998:400:207-28.

41. Mori K, Ozaki E, Zhang B, Yang L, Yokoyama A, Takeda I, Maeda N, Sakanaka $M$, Tanaka J. Effects of norepinephrine on rat cultured microglial cells that express a1, a2, b1, b2 adrenergic receptors. Neuropharmacol. 2002;43:1026-34.

42. Nair A, Bonneau RH. Stress-induced elevation of glucocorticoids increases microglial proliferation through NMDA receptor activation. J Neuroimmunol. 2006;171:72-85

43. Nedergaard M. Garbage Truck of the Brain. Science. 2013;340:1529-30.

44. Page ME, Elizabeth D, Abercrombie D. An analysis of the effects of acute and chronic fluoxetine on extracellular norepinephrine in the rat hippocampus during stress. Neuropsychopharmacology. 1997;16:419-25.

45. Perry VH, Brown MC, Gordon S. The macrophage response to central and peripheral nerve injury. A possible role for macrophages in regeneration. $J$ Exp Med. 1987;165:1218-23.

46. Pietrogrande G, Mabotuwana N, Zhao Z, Abdolhoseini M, Johnson SJ, Nilsson M, Walker FR. Chronic stress induced disturbances in Laminin: a significant contributor to modulating microglial pro-inflammatory tone? Brain Behav Immun. 2018:68:23-33.

47. Qian L, Hu X, Zhang D, Snyder A, Wu HM, Li Y, Wilson B, Lu RB, Hong JS, Flood PM. $\beta 2$ adrenergic receptor activation induces microglial NADPH oxidase activation and dopaminergic neurotoxicity through an ERKdependent/protein kinase A-Independent pathway. Glia. 2009:57:1600-9.

48. Rana I, Stebbing M, Kompa A, Kelly D, Krum H, Badoer E. Microglia activation in the hypothalamic PVN following myocardial infarction. Brain Res. 2010;1326:96-104.

49. Reus GZ, Fries GR, Stertz L, Badawy M, Passos IC, Barichello T, Kapczinski F, Quevedo J. The role of inflammation and microglial activation in the pathophysiology of psychiatric disorders. Neuroscience. 2015:300:141-54. 50. Sapolsky RM. Why stress is bad for your brain. Science. 1996;273:749-50. 
51. Shimizu Y, Sugama S, DeGiorgio LA, Cho BP, Joh TH. Cell-type specific signal transduction and gene regulation via mitogen-activated protein kinase pathway in catecholaminergic neurons by restraint stress. Neuroscience. 2004;129:831-9.

52. Stein DJ, Vasconcelos MF, Albrechet-Souza KMM, de Almeida RMM. Microglial over-activation by social defeat stress contributes to anxiety- and depressive-like behaviors. Front Behav Neurosci. 2017;11:207.

53. Stence N, Waite M, Dailey ME. Dynamics of microglial activation: a confocal time-lapse analysis in hippocampal slices. Glia. 2001;33:256-66.

54. Stoll G, Trapp BD, Grifin JW. Macrophage function during Wallerian degeneration of rat optic nerve: clearance of degenerating myelin and la expression. J Neurosci. 1989;9:2327-35.

55. Suemaru S, Dallman MF, Darlington DN, Cascio CS, Shinsako J. Role of alpha-adrenergic mechanism in effects of morphine on the hypothalamopituitary-adrenocortical and cardiovascular systems in the rat. Neuroendocrinol. 1989;49:181-90.

56. Sugama S, Kim Y, Baker H, Tinti C, Kim H, Joh TH, Conti B. Tissue-specific expression of rat IL-18 gene and response to adrenocorticotropic hormone treatment. J Immunol. 2000;165:6287-92.

57. Sugama S, Fujita M, Hashimoto M, Conti B. Stress induced morphological microglial activation in the rodent brain: involvement of Interleukin-18. Neuroscience. 2007;146:1388-99.

58. Sugama S, Takenouchi T, Fujita M, Kitani H, Conti B, Hashimoto M. Corticosteroids limit microglial activation occurring during acute stress. Neuroscience. 2013;232:13-20.

59. Sugama S, Sekiyama K, Kodama T, Takamatsu Y, Takenouchi T, Hashimoto $\mathrm{M}$, Conti B, Kakinuma Y. Chronic restraint stress triggers dopaminergic and noradrenergic neurodegeneration: possible role of chronic stress in the onset of Parkinson's disease. Brain Behav Immun. 2016;51:39-46.

60. Tan KS, Nackley AG, Satterfield K, Maixner W, Diatchenko L, Flood PM. Beta2 adrenergic receptor activation stimulates proinflammatory cytokine production in macrophages via PKA-and NF-kappaB-independent mechanisms. Cell Signal. 2007;19:251-60.

61. Tanaka KF, Kashima H, Suzuki H, Ono K, Sawada M. Existence of functiuonal $\beta 1$ and $\beta 2$ adrenergic receptors on microglia. J Neurosci Res. 2002;70:232-7.

62. Tanaka T, Yokoo H, Mizoguchi K, Yoshida M, Tsuda A, Tanaka M. Noradrenaline release in the rat amygdala is increased by stress: studies with intracerebral microdialysis. Brain Re. 1991;544:174-6.

63. Tetreault NA, Hakeem AY, Jiang S, Williams BA, Allman E, Wold BJ, Allman JM. Microglia in the cerebral cortex in autism. J Autism Development Dis. 2012;42:2569-84

64. Tomozawa $Y$, Yabuuchi K, Inoue T, Satoh M. Participation of CAMP and CAMP-dependent protein kinase in $\beta$-adrenoceptor-mediated interleukin-1 $\beta$ mRNA induction in cultured microglia. Neurosci Res. 1995;22:399-409.

65. Torres-Platas SG, Cruceanu C, Chen GG, Tureck G, Mechawar N. Evidence for increased microglial priming and macrophage recruitment in the dorsal anterior cingulated white matter of depressed suicides. Brain Behav Immun. 2014:42:50-9.

66. Tynan RJ, Naicker S, Hinwood M, Nalivaiko E, Buller KM, Pow DV, Day TA, Walker FR. Chronic stress alters the density and morphology of microglia in a subset of stress-responsive brain region. Brain Behav Immun. 2010;24:1058-67.

67. Wadhwa M, Chauhan G, Roy K, Sahu S, Deep S, Jain V, Kishore K, Ray K, Thakur L, Panjwani U. Caffeine and modafinil ameliorate the neuroinflammation and anxious behavior in rats during sleep deprivation by inhibiting the microglia activation. Front Cell Neurosci. 2018;12:49.

68. Walker FR, Nilsson M, Jones K. Acute and chronic stress-induced disturbances of microglial plasticity, phenotype and function. Curr Drug Targets. 2013;14:1262-76.

69. Walter TJ, Vetreno RP, Crews FT. Alcohol and stress activation of microglia and neurons: brain regional effects. Alcohol Clin Exp Res. 2017;41:2066-81.

70. Wang B, Wang Y, Wu Q, Huang H, Li S. Effects of a2A adrenoceptors on norepinephrine secretion from the locus coeruleus during chronic stressinduced depression. Front Neurosci. 2017;11:243.

71. Wang J, Li J, Sheng X, Zhao H, Cao XD, Wang YQ, Wu GC. Betaadrenoceptor mediated surgery-induced production of pro-inflammatory cytokines in rat microglia cells. J Neuroimmunol. 2010;223:77-83.

72. Wohleb ES, Hanke ML, Corona AW, Powell ND, Stiner LM, Bailey MT, Nelson RJ, Godbout JP. Sheridan JF: $\beta$-Adrenergic receptor antagonism prevents anxiety-like behavior and microglial reactivity induced by repeated social defeat. J Neurosci. 2011;31:6277-88.
73. Xie L, Kang H, Zu Q, Chen MJ, Liao Y, Thyagarajan M, O’Donnell J, Christensen DJ, Nicholson C, lliff JJ, Takano T, Deane R, Nedergaard M. Sleep drives metabolite clearance from the adult brain. Science. 2013;342:373-7.

74. Yabuuchi K, Maruta E, Yamamoto J, Nishiyori A, Takami S, Minami M, Satoh M. Intracerebroventricular injection of isoproterenol produces its analgesic effect through interleukin-1 $\beta$ production. Eur J Pharmacol. 1997;334:133-40.

75. Yirmiya R, Rimmerman N, Reschef R. Depression as a microglial disease. Trends Neurosci. 2015;38:637-58.

76. Yoshii T, Oishi N, Ikoma K, Nishimura I, Sakai Y, Matsuda K, Yamada S, Tanaka M, Kawata M, Narumoto J, Fukui K. Brain atrophy in the visual cortex and thalamus induced by severe stress in animal model. Sci Rep. 2017;7:12731.

\section{Publisher's Note}

Springer Nature remains neutral with regard to jurisdictional claims in published maps and institutional affiliations.

\section{Ready to submit your research? Choose BMC and benefit from:}

- fast, convenient online submission

- thorough peer review by experienced researchers in your field

- rapid publication on acceptance

- support for research data, including large and complex data types

- gold Open Access which fosters wider collaboration and increased citations

- maximum visibility for your research: over $100 \mathrm{M}$ website views per year

At $\mathrm{BMC}$, research is always in progress.

Learn more biomedcentral.com/submissions 